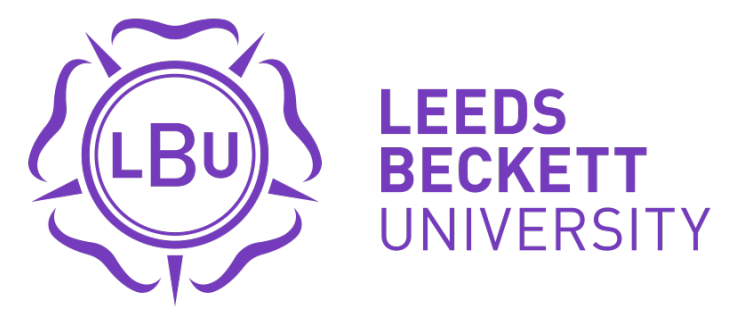

Citation:

Abdelhadi, Y and Dulaimi, M and Bajracharya, A (2018) Factors Influencing the Selection of Delay Analysis Methods in Construction Projects in UAE. International Journal of Construction Management. ISSN 1562-3599 DOI: https://doi.org/10.1080/15623599.2018.1435155

Link to Leeds Beckett Repository record:

https://eprints.leedsbeckett.ac.uk/id/eprint/4691/

Document Version:

Article (Accepted Version)

This is an Accepted Manuscript of an article published by Taylor \& Francis in International Journal of Construction Management on 17 February 2018, available online: http://www.tandfonline.com/10.1080/15623599.2018.1435155

The aim of the Leeds Beckett Repository is to provide open access to our research, as required by funder policies and permitted by publishers and copyright law.

The Leeds Beckett repository holds a wide range of publications, each of which has been checked for copyright and the relevant embargo period has been applied by the Research Services team.

We operate on a standard take-down policy. If you are the author or publisher of an output and you would like it removed from the repository, please contact us and we will investigate on a case-by-case basis.

Each thesis in the repository has been cleared where necessary by the author for third party copyright. If you would like a thesis to be removed from the repository or believe there is an issue with copyright, please contact us on openaccess@leedsbeckett.ac.uk and we will investigate on a case-by-case basis. 


\title{
Factors Influencing the Selection of Delay Analysis Methods in Construction Projects in UAE
}

\begin{abstract}
Several delay analysis methods (DAMs) have been developed and used in the construction industry in order to analyse the causes and effects of delay events. In this research, a number of commonly used DAMs, in the specific context of $\mathrm{UAE}$, are investigated by exploring the factors influencing their selection decisions as well as the process of making such a decision. A total of eight expert respondents from five different projects in the UAE were selected who provided critical insight into the decision making process adopted in practice to select a DAM. The individual project case analysis as well as the cross case analysis helped to identify a number of factors that influence the selection of DAMs in UAE projects. Some of the main identified factors were the attitude of the client, experience of the delay analyst, reputation and impartiality of the delay analyst, complexity of the project, and cost and timing of performing the analysis. The research argues that such an important decision process that can have a serious impact on the success of a commercial venture requires individual organisations to develop and adopt clear guidelines on how such decisions are made to protect its commercial interests.
\end{abstract}

Keywords: Delay analysis methods, selection of DAMs, construction projects, qualitative data, UAE.

\section{Introduction}

Delay in the progress of works is a common problem that occurs in most construction projects (Zainal et al. 2017 and Al-Fadhali et al. 2018). The causes of delay could be wide ranging (Vidalis and Najafi 2002; Assaf and Al-Hejji 2006) and interrelated ((Al-Fadhali \& Zainal (2017) and Zarei et al. 2017), and the consequences of delay could generate liabilities to the parties involved (Perera et al. 2016 and Al-Fadhali et al. 2017). The project would suffer further disruption if the different parties failed to 
agree on the issues as relationships and cooperation level may be affected (Sambasivan and Soon 2007). Where the consequences of a delay are perceived to be significant (AlFadhali \& Zainal (2017) and Al-Fadhali et al. 2018), the relevant parties have to be assured of the adequacy of the method used in delay analysis. The fast moving pace of project development in the United Arab Emirates (UAE) fuelled by the ambitious plan to develop the country's infrastructure and facilities where current active construction projects are estimated to more than 800 billion US Dollars (Arabian Business 2017) puts serious pressure on the involved parties to resolve such matters quickly. It is not surprising that this issue has attracted significant interest from researchers (Ruqaishi and Bashir 2015; Emam et al. 2014) when research showed that the average estimated delay amounted to $39 \%$ of the contractual time in the Kingdom of Saudi Arabia (Elawi et al. 2016).

Delay analysis is generally done to determine the critical causes of delay and to allow for proper apportioning of liabilities between different parties ( $\mathrm{Ng}$ et al. 2004). Avalon (2017) and (Al-Fadhali et al. 2018) highlighted that using an inadequate delay analysis method (DAM) may have substantial consequences such as distraction from the factual entitlement issues, undermining of the credibility of the analysis, lowering the chances of recovery and adding unnecessary costs.

There are different DAMs available for use that have variable strengths and requirements. In addition, as projects and delay events vary in nature and complexity, it can be a complicated exercise to determine causes, effects and liabilities of delay. Therefore, determining the most appropriate DAM to use on a particular project for a particular delay event becomes a tricky issue (Assaf and Al-Hejji 2006). Williams (2003) argued that the applicability of the methods is very context specific and none of them can be universally fit for use in all situations. The choice of the method for 
analysing delays would affect the results of analysis, and as such, the knowledge on the factors that affect the choice of the methods is highly critical (Nelson and Livengood, 2017).

The aim of this research is to investigate current practices in the UAE construction industry in the selection and use of DAMs. The objectives are to examine the effectiveness of currently used methods in the analysis of delays and explore the factors influencing the decision to select the DAM to be used in a particular project. A qualitative research methodology has been utilized to analyse the data collected from delay analysis experts working in five different construction projects in UAE. This research intends to develop knowledge to better understand the negotiation and decision making processes on the choice of acceptable and effective DAM.

\section{A Review of Delay Analysis Methods (DAMs)}

D'Onofrio (2015) argues that the name and type of DAM do not really matter as long as delay analysts explain and justify their selection and performance. Yang and Kao (2012) and Avalon (2017) noted that all DAMs require assumptions and contain theoretical forecasts and subjective assessments. SCL (2002) and Arditi and Pattanakitchamroon (2006) suggested four DAMs that are most common in construction industry: (i) As Planned vs. As Built (APvAB), (ii) Impacted as Planned (IAP), (iii) Collapsed as Built (CAB), and (iv) Time Impact Analysis (TIA) methods. SCL (2017 further suggested the Time Slice Windows Analysis (TSWA) and the Retrospective Longest Path Analysis (RLPA) as common and acceptable in construction industry and updated the As Planned vs. As Built (APvAB) method to As Planned vs. As Built windows analysis method. 
APvAB method compares the planned activities (baseline) with the as-built activities, and as such, it requires a baseline and an as-built schedule or as-built records. Yusuwan and Adnan (2013) describe it as the most preferred method as it is simple and produces fair and reasonable results. SCL (2015) and SCL (2017) recommended using this method in windows when performing the analysis distant from the event. Its main features are that it does not present a complex analysis nor does it require any computerised software. However, it is based on what can be considered as highly subjective views and assumptions. While it is relatively easy to perform, it requires analysts to have relevant experience and it may not be sufficient to deal with concurrent delays or the dynamic nature of critical path (Braimah and Ndekugri 2008).

The IAP method simply adds all delay events on the baseline schedule in a prospective way on the assumption that the baseline logic, sequence and durations have not changed (Arditi and Pattanakitchamroon 2006). IAP may be sufficient to predict future delays but it will not give adequate results when analysing on-going or completed projects (Braimah and Ndekugri 2008). Kao and Yang (2009) suggested alternative names for the IAP method: 'as planned', 'what-if', 'impacted baseline schedule', 'as planned plus delay analysis' and the 'affected baseline schedule' methods. The IAP method requires a baseline schedule and knowledge of the delay events and it is not recommended for complex cases and completed projects.

Collapsed/'But for’ As-Built Analysis (CAB) method analyses the delay using the final as built schedule, or by creating an as built schedule including all network logic along with all delay events and their impacts and then excluding the impact of the delay events to see what would have been the case 'but for' such delay events (Braimah and Ndekugri 2008). This method is moderately complex and requires an as-built schedule and knowledge of the delay events. It is suitable for complex cases but cannot 
deal with concurrency issues and the changing nature of the critical path.

TIA is a dynamic method that allows for initially creating a separate subnetwork for each of the events, which can be agreed between the parties, and then these subnets can be inserted into the project-updated schedules in each relevant time-period. In the final time-period, there will be a fully impacted schedule containing all delay events and considering all as built data (SCL 2002 and Livengood 2017)). TIA is considered as the preferred method but not when the case of analysis is distant from the events (SCL 2015 and SCL 2017). It considers project delays regardless of the originator or the type of the delay and encourages the parties to keep good records and to update the project schedule on regular basis. However, the method requires complex analysis that might consume substantial time and effort. As such, its use will be highly dependent on the availability and the quality of the project records (Arditi \& Pattanakitchamroon 2006).

SCL (2017) describes the Time Slice Windows Analysis method as an observational method where the delay analyst reviews the available progress updates and forms a view on the critical path and causes of delay. Avalon (2017) highlighted that such observational methods may not adequately deal with concurrency and that the contemporaneous programmes would need to be validated to ensure they yield accurate results.

Finally, SCL (2017) highlighted that in the Retrospective Longest Path Analysis, the delay analyst would determine the retrospective as-built critical path of the project by tracing the longest continuous path backward from the actual completion date. Avalon (2017) argued that the retrospective observational methods may not capture the contemporaneous critical path.

A summary of the reviewed DAMs has been presented in Table 1. 
Table 1. Summary of DAMs

\begin{tabular}{|l|l|l|}
\hline S. N. & Method & Brief Description \\
\hline 1. & $\begin{array}{l}\text { As-Planned vs. As-Built Windows } \\
\text { Analysis (APvAB) }\end{array}$ & $\begin{array}{l}\text { Observation of the difference between an as-planned and an as- } \\
\text { built schedule. }\end{array}$ \\
\hline 2. & Impact As-Planned (IAP) & $\begin{array}{l}\text { It is based on the theory that the completion date can be } \\
\text { determined by adding the delays into the as-planned schedule. }\end{array}$ \\
\hline 3. & Collapsed As-Built (CAB) & $\begin{array}{l}\text { Effects of delays are "subtracted" from an as-built schedule to } \\
\text { determine what would have occurred without the delay events. }\end{array}$ \\
\hline 4. & Time Impact Analysis (TIA) & $\begin{array}{l}\text { Assumes that delay impacts to a project can be assessed by } \\
\text { running a series of analyses on schedule updates. }\end{array}$ \\
\hline 5. & $\begin{array}{l}\text { Time Slice Windows Analysis } \\
\text { (TSWA) }\end{array}$ & $\begin{array}{l}\text { Delay is measured by observing the forecast delay in the available } \\
\text { progress updates, at various time intervals }\end{array}$ \\
\hline 6. & $\begin{array}{l}\text { Retrospective Longest Path } \\
\text { Analysis (RLPA) }\end{array}$ & $\begin{array}{l}\text { The critical path is determined by tracing the longest continuous } \\
\text { path backward from the actual completion date. }\end{array}$ \\
\hline
\end{tabular}

\section{Factors to Consider While Selecting Delay Analysis Methods}

The Society of Construction Law (SCL) delay and disruption protocol (SCL 2002), its second edition (SCL 2017) and the practice 29R-03 recommended by American Institute of Advancement of Cost Engineering International (AACEI 2011) are the most recognized documents that provide information on delay analysis types and selection factors. However, they do not provide sufficient guidance as to how such factors influence the selection and application of DAMs (Nelson and Livengood 2017).

Williams (2003) and Avalon (2017) noted that before selecting a DAM, questions should be asked to confirm which method can give the desired outcome and whether the project circumstances are suitable for performing such method(s). Braimah and Ndekugri (2008) identified 18 factors affecting the selection of the appropriate DAM and grouped them into six main categories. These categories were relating to the project baseline quality and features, contractual obligations, project nature and circumstances, cost efficiency of the method, availability of records and the prospective 
of performing the analysis in terms of time. SCL (2002) outlined ten factors that have to

be considered when selecting the appropriate DAM. After reviewing similar literature,

some key factors have been identified and summarised in Table 2. This knowledge

should form the basis for the decision making process to select the appropriate DAM.

The focus of this research is to investigate this decision making process as well as to

examine the usefulness of such factors in the context of UAE projects.

Table 2. Identified Key Factors

\begin{tabular}{|c|c|c|}
\hline S. $\mathbf{N}$. & Factors & Source Literature \\
\hline 1. & Data, information and records available & $\begin{array}{l}\text { Bubshait and Cunningham (1998) } \\
\text { Alkass et al. (1995) } \\
\text { Williams (2003) } \\
\text { Arditi and Pattanakitchamroon (2006) } \\
\text { Braimah and Ndekugri (2008) } \\
\text { Yusuwan and Adnan (2013) } \\
\text { Avalon (2017) } \\
\text { Nelson and Livengood (2017) }\end{array}$ \\
\hline 2. & Availability and quality of baseline schedule & $\begin{array}{l}\text { Arditi and Pattanakitchamroon (2006) } \\
\text { Braimah and Ndekugri (2008) }\end{array}$ \\
\hline 3. & Contractual obligations and Legal Considerations & $\begin{array}{l}\text { SCL (2002) } \\
\text { Arditi and Pattanakitchamroon (2006) } \\
\text { Braimah and Ndekugri (2008) } \\
\text { Avalon (2017) } \\
\text { Nelson and Livengood (2017) }\end{array}$ \\
\hline 4. & Project nature, complexity and circumstances & $\begin{array}{l}\text { Braimah and Ndekugri (2008) } \\
\text { Avalon (2017) }\end{array}$ \\
\hline 5. & Nature, types and number of delay events & $\begin{array}{l}\text { Kraiem and Diekmann (1989) } \\
\text { SCL (2002) } \\
\text { Bubshait and Cunningham (1998) } \\
\text { Kao and Yang (2009) }\end{array}$ \\
\hline 6. & Skills and professional judgment of the analyst & $\begin{array}{l}\text { SCL (2002) } \\
\text { Braimah and Ndekugri (2008) } \\
\text { Avalon (2017) } \\
\text { Nelson and Livengood (2017) }\end{array}$ \\
\hline 7. & The attitude of the opponent party & $\begin{array}{l}\text { Braimah and Ndekugri (2008) } \\
\text { Avalon (2017) }\end{array}$ \\
\hline 8. & $\begin{array}{l}\text { Time, cost and resource constraints for performing the } \\
\text { analysis }\end{array}$ & $\begin{array}{l}\text { Bubshait and Cunningham (1998) } \\
\text { SCL (2002) } \\
\text { Arditi and Pattanakitchamroon (2006) } \\
\text { Braimah and Ndekugri (2008) } \\
\text { Avalon (2017) } \\
\text { Nelson and Livengood (2017) }\end{array}$ \\
\hline 9. & Strengths and shortcomings of the method & $\begin{array}{l}\text { Arditi and Pattanakitchamroon (2006) } \\
\text { Kao and Yang (2009) } \\
\text { Avalon (2017) }\end{array}$ \\
\hline 10. & Status of project and point of time & $\begin{array}{l}\text { Arditi and Pattanakitchamroon (2006) } \\
\text { Braimah and Ndekugri (2008) } \\
\text { SCL (2015) }\end{array}$ \\
\hline 11. & Concurrent delays, disruption and acceleration issues & $\begin{array}{l}\text { Williams (2003) } \\
\text { Mohan and Al-Gahtani (2006) }\end{array}$ \\
\hline
\end{tabular}




\begin{tabular}{|l|l|l|}
\hline 12. & Purpose and reasons for delay analysis & $\begin{array}{l}\text { Braimah and Ndekugri (2008) } \\
\text { Avalon (2017) } \\
\text { Nelson and Livengood (2017) }\end{array}$ \\
\hline 13. & Ownership of the float & $\begin{array}{l}\text { Arditi and Pattanakitchamroon (2006) } \\
\text { Mohan and Al-Gahtani (2006) } \\
\text { Kao and Yang (2009) }\end{array}$ \\
\hline 14. & Software used/scheduling settings & Arditi and Pattanakitchamroon (2006) \\
\hline
\end{tabular}

\section{The Study}

The emphasis of this study is to understand how in practice decisions are made to select the most appropriate DAM for a construction project. Interpretive data from industry experts were required in order to develop broad and holistic knowledge on DAMs. The naturalistic and interpretivist research orientation requires qualitative approach as it provides the advantage of direct engagement with the subject of research, unlike the positivist or quantitative approach that emphasise the study of natural setting rather indirectly (Denzin and Lincoln 2000). Qualitative research methods actually provide an opportunity to engage subjects to explain their perception and experience of making decisions. The qualitative approach will also allow the proper investigation of the topic by analysing the interpretation of professionals in terms of their real life experience and understanding (Fellows and Liu 2008). It is because of these reasons, a qualitative method was used in this research.

A total of eight experts in UAE who could provide insight into the decision making process regarding the selection of DAMs were identified and requested to participate in the research. They agreed and informed about a set of five projects in UAE in which they had worked. A series of face-to-face semi-structured interviews were conducted to collect the relevant data. The interviews mainly focused on the following issues:

a. how the company made decisions on the method to be used to assess delays in their projects, 
b. what were the key factors that influenced the choice of method, and

c. in what way has the selected method enabled or impeded the effort to assess delays more effectively and achieve the desired results.

The collected interview data were organised and transcribed under the respective interviewees and their corresponding projects. The cases were the delay events in the five different projects. The data were transcribed in terms of the narration provided by the interviewees, and data were analysed by using mainly the narrative approach.

The respondent expert interviewees and case projects details are as shown below in Table 3.

Table 3. Case Projects and Interviewees

\begin{tabular}{|l|l|l|}
\hline S. N. & Project & Interviewees (Years of Work Experience) \\
\hline 1. & A: A five-star hotel & $\begin{array}{l}\text { A1, Project planner (12 years) } \\
\text { A2, Delay analyst (30 years) } \\
\text { A3, Delay analyst (29 years) }\end{array}$ \\
\hline 2. & B: An international school complex & $\begin{array}{l}\text { B1, Project planner (15 years) } \\
\text { B2, Delay analyst (30 years) }\end{array}$ \\
\hline 3. & C: A highway & C1, Project planner (15 years) \\
\hline 4. & D: A sewage treatment plant & D1, Delay analyst (32 years) \\
\hline 5. & E: A residential tower & E1, Project planner (7 years) \\
\hline
\end{tabular}

\section{Analysis of Individual Project Case Data}

\section{Project A - A Five-Star Hotel}

Table 4. Summary of the Five-Star Hotel Project

\begin{tabular}{|l|l|}
\hline Location: UAE & Approximate value: 65m USD \\
\hline Planned start date: 8 March 2006 & Actual start: 8 March 2006 \\
\hline Planned completion date: 17 October 2007 & Actual completion: 28 July 2010 \\
\hline $\begin{array}{l}\text { Main cause of delay: Late design and variation } \\
\text { orders }\end{array}$ & $\begin{array}{l}\text { Purpose of delay analysis: Support a statement of claim in } \\
\text { an arbitration case for an extension of time (EoT) dispute }\end{array}$ \\
\hline
\end{tabular}


Project A is a five-star hotel, which is one of the iconic projects in Dubai, UAE (See Table 4 for summary of the project). The records of the project revealed that the first claim filed by the contractor used the IAP delay analysis method and the claim was never agreed by the client. A dispute cropped-up and an arbitration case was then filed where the float mapping method was used. At a later stage of the arbitration, a new expert was involved and the TIA method was used. The case was then settled. The IAP method concluded that the contractor was entitled for compensation of damages during the whole prolonged period of 1109 days. Both the float mapping and the TIA methods concluded that project was prolonged by 1173 days. The float mapping determined that the contractor was entitled to the full 1173 days of extension of time (EoT) whereas the TIA method concluded that the contractor was entitled for 913 days of EoT only.

\section{Project Planner A1}

A1 informed that in order to decide on which DAM to use, the first thing he looked at was purpose of the analysis and whether the contract specified the method that can be used in the analysis of delays. The purpose was to support the contractor's EoT entitlement and the contract did not require any specific method. He then explained that at that stage he chose IAP as a suitable method and it was also the preferred method in the contractor's organization. He was also under pressure to complete the analysis in a very short period of time and he was working with the perception that no detailed analysis would be required as the client was aware of the delay events and was willing to settle. He performed the whole analysis in six weeks.

A1 considered the issue of project complexities of the delay events during the analysis process rather than in making the method selection decision. When the researcher shared the list of 14 main identified factors presented in Table 1, A1 said that he did consider most of the factors before selecting the method, but some of them he 
missed or ignored - probably because of that, he thought the client rejected his analysis. For example, he completely ignored concurrent delay issues and therefore selected a simple method. He indicated that he selected IAP as it considers only the delay due to client and it would give the contractor more EoT entitlement.

A1 also tried to understand the attitude of the opponent party, i.e. the client, before selecting the method, but his conclusion turned out to be misleading as the client, even though he was willing to settle the case, still wanted a fairly complex analysis before he would approve the EoT entitlement. When A1 was asked about how the selected method enabled him to assess delays more effectively and achieve the desired results, he explained that the analysis using of IAP was quick and easy. In his view, the results of his analysis were very reasonable considering the relatively short period of available time. However, the client and the project engineer did not accept the results of the analysis claiming that it was too theoretical and that it did not address complexities. A1 opined that the real reason for the rejection was that the client was trying to undermine the claim so that settlement could be made with shorter EoT.

It was noted that A1 failed to consider the concurrent delays, disruption and acceleration factors and misjudged the attitude of the opponent party and the purpose of the analysis. In fact, it appears that A1's decision for selection of the method was influenced by the contractor's preference of performing analysis that can produce maximum EoT entitlement. This could be viewed as a hidden purpose of the analysis but it raises a question of the impartiality of his decision.

A1 was finally asked about why he did not perform a revised analysis that could satisfy the client's requirements and achieve the desired results. He explained that he did 
not have sufficient experience to perform a complex method such as TIA. It therefore appears that the contractor's decision to involve another expert delay analysis consultant was to address A1's inadequate experience and importantly to demonstrate sincere effort in performing the analysis objectively.

\section{Delay Analyst A2}

As a result of the client's rejection, the contractor hired A2 as an independent delay analysis consultant and asked him to review the performed analysis and produce a report of his own findings including a revised delay analysis, if necessary. A2 informed that the first thing he did was to review the available records along with the baseline and as-built schedules. His intention was to utilize the float mapping method as, in his view, it was the best method in finding out the real critical path throughout the project period. A2 highlighted that, in his view, there was no right or wrong answer to any kind of delay analysis. The real question was whether all facts were considered in a fair and appropriate way. A2 confirmed that he generally used the float mapping method in all projects, but he did consider various factors in deciding the level of detail of analysis of the project delay. While the adoption of the DAM appeared to be as per the subjective opinion of $\mathrm{A} 2$, his consideration of the factors as part of the decision was the level of detail of analysis rather than the selection of the method itself. The factors A2 considered were basically the availability and accessibility of records, the complexity of the project, his expertise in float mapping method, status of the project and the purpose of the analysis. A2 also highlighted that one of the major factors to consider in this method was the ownership of float, as it would lead the float mapping delay analysis in getting true picture of what actually happened in the project. A2 also explained that the method, although might take longer time and require specific experience when compared to other methods, demonstrated the actual critical paths and the delays 
occurred on such paths in the project. This enabled him to objectively analyse the delay and assign responsibilities to the project parties. A2 informed that it took him 14 weeks to perform the analysis.

Although the float mapping method is a fairly complex method and A2 was an independent delay analysis consultant, the client and the project engineer were still not convinced with the results. The concern of the client and the project engineer was that the analysis lacked consideration of the concurrent delay issues in contrary to A2's argument that he did consider all concurrent delay events as part of the analysis process. He explained that he attended various meetings with the client and tried to persuade them with the analysis results but they were reluctant to accept the results particularly on the ground that no critical delay caused by the contractor was considered in the analysis.

\section{Delay Analyst A3}

After making various attempt to resolve the matter amicably with the client, the contractor declared that a dispute had arisen and filed an arbitration case against the client. A3 was involved in the project as an expert to assist the arbitration tribunal in making their decision on the dispute over the project claim. A3 explained that his appointment was directly made by the arbitration tribunal to ensure impartiality and that he was instructed to rely on inputs from A1 and A2 but not their opinion. It could be seen here that A3 described the results of A1 and A2's analysis as an 'opinion' which supports the notion that the selection of the method and the produced results contained a lot of subjective views. This also explains why each delay analyst selects different method even though the same factors are considered, and why each delay analyst may produce different results even though the same facts are considered. A3 agreed with this statement. However, knowing that delay analysis had already been performed twice in 
this project, A3 said that it was his intention to review the performed analysis and utilize the available information as much as possible before deciding which method should be used and whether revised analysis was required.

His first impression was that the complexity in the project design and delay events were not considered when the two methods were selected. A3 explained that technical input should have been acquired in order to adequately estimate the impact of the complex delay events. A3 highlighted the fact that there were some concurrent delay events and that the events were spread over a long period of time. As such, a periodic delay analysis method such as TIA was to be considered. A3 commented that this did not necessarily mean A1's and A2's selected methods or results were wrong. It was just that A3 felt the delay analyst should use the method that could best describe what actually happened. He also added that A1's selection of IAP method assumed that the project suffered only from delay events caused by the client and that the contractor did not exert any mitigation effort. The usual defense of such analysis is that the client should make their own analysis and posit the case if they believe the project suffered from delays other than those caused by them. It is worth noting here as commented on the analysis of A2's input above that the TIA performed by A3 was more appropriate when considering the factor of the current status of the project, which further explains why the analysis of A1 above may have been rejected. In relation to the float mapping analysis, A3 said that he had two main issues with it. The first, it was too complex and not common in the industry. The second, it heavily relied on the logic of the schedule which was rarely accurate or fixed as the sequence of activities changes as the contractor makes progress in the works further.

A3 selected and performed TIA, and he said that the method revealed that the contractor's concurrent delays were critical at some stages of the project. He however 
said that this may be the result of the way he performed the analysis rather than the selection of the method itself. A3 also noted that it took him around 25 weeks to review the project documents and perform the revised analysis. He also noted that it could have taken more time if the previously performed analysis were not available. As an independent expert, A3 had to make a choice to take all the time necessary to perform the analysis he believes is most appropriate. The case however was different with A1 and A2 who had time and cost as limiting constraints in their analysis.

During the arbitration process, the client also appointed another third party delay analysis consultant who also performed a separate TIA. A3 explained that they had some disagreement over the impact of some of the events but they were in agreement over the selection of the method and the way of performing it. Eventually, the consultant agreed on the overall delay period of the project which was 1173 days, and the contractor was entitled for 913 days of EoT as he was liable for 260 days of the delay.

\section{Project B - An International School Complex}

Table 5. Summary of the International High School Project

\begin{tabular}{|l|l|}
\hline Location: UAE & Approximate value: 120m USD \\
\hline Planned start date: 1 September 2007 & Actual start: 1 April 2009 \\
\hline Planned completion date: 2 January 2009 & Actual completion: 2 April 2011 \\
\hline $\begin{array}{l}\text { Main cause of delay: Late no objection certificates } \\
\text { (NoCs) on design, issues with the technical design, and } \\
\text { variation orders }\end{array}$ & $\begin{array}{l}\text { Purpose of delay analysis: Support the negotiations } \\
\text { through a mediation process for an EoT and project } \\
\text { acceleration }\end{array}$ \\
\hline
\end{tabular}

In the international high school project (summary of which is given in Table 5), there were delay in getting design 'No Objection Certificates' (NoCs) by the client and there were issues with the technical design as well. The client also issued multiple variation orders for changes in the design. The records of the project show that a claim 
was submitted by the contractor to the project engineer using IAP method. This claim was rejected by the engineer stating that no consideration was given to the concurrent delay, and that the effects of the client's delay events were exaggerated. A third party consultant was appointed by the contractor at a later stage during the settlement negotiation process and he used the TIA method. The case was eventually settled through mediation. Both methods concluded that the contractor was entitled to 820 days of EoT.

\section{Project Planner B1}

Project planner B1 did IAP analysis and explained that IAP was selected because he was aware that no concurrent delay occurred in the project since the beginning. B1 further explained that the project was complex but the events were fairly simple though they were too many. B1 noted that he performed and presented the analysis professionally and he was satisfied with the results as it provided the basis for the contractor's EoT entitlement. B1 highlighted that the client's representative was convinced with the results but he could not persuade his stakeholders that the contractor had no concurrent delays. At this stage the contractor was willing to do whatever it takes to settle the claim amicably as it was known that the cost of the arbitration or legislation processes would be too expensive. Through direct negotiations with the client, it was agreed that a third party consultant be hired by the contractor to perform a revised analysis that can demonstrate that there were no critical delays caused by the contractor. B1 highlighted here that he could have performed TIA if he was requested to do so but he understood that the client's internal stakeholders wanted a third party report from an independent expert so that they could rely on in their decision. 


\section{Project Planner B2}

Project planner B2 was hired by the contractor as an independent consultant to produce a report demonstrating that there was no critical delay in the project for which the contractor was responsible. The project had been already handed over and the school was in operation at that stage. B2 explained that the first thing he did was reviewing the already performed analysis and the whole project records with particular attention to the baseline programme. B2 further explained that as an expert, he immediately noticed it was unlikely that the contractor's concurrent delays, if any, would cause critical delay to the project. However, as he was aware that the client was not willing to settle without having a sophisticated delay analysis method that could establish that no concurrent delays were there, he decided to perform TIA in detail.

TIA is generally applicable in all cases but it requires more time and effort than other methods. However, B2 managed to produce the revised analysis in only 5 weeks. A point worth noting here is that there was no specific time period within which a method was required to be performed. However the required time frame would depend on project nature and circumstances along with other factors influencing the selection of DAM. For example, TIA took 6 months in project A but it took only 5 weeks in Project B.

B2 concluded that the results of IAP were correct and there were no critical concurrent delay events from the side of contractor. B2 commented that sometimes the results will be clear since the beginning of analysis but you need to provide the parties with an analysis that can make them able to justify their decisions within their own organizations. 


\section{Project C-A Highway}

Table 6. Summary of the Highway Project

\begin{tabular}{|l|l|}
\hline Location: UAE & Approximate value: 113m USD \\
\hline Planned start date: 8 July 2009 & Actual start: 8 July 2009 \\
\hline Planned completion date: 1 December 2011 & Actual completion: 1 February 2012 \\
\hline $\begin{array}{l}\text { Main cause of delay: Late selection and approval of the } \\
\text { materials and equipment }\end{array}$ & Purpose of delay analysis: Support an EoT claim \\
\hline
\end{tabular}

Project C, a highway project, summary of which is given in Table 6 , suffered with a number of delays in approving the materials and equipment. The project records reveal that a claim was submitted by the contractor using the TIA method. The claim was for 62 days of EoT and it was eventually accepted by the project engineer and client.

\section{Project Planner C1}

Project planner $\mathrm{C} 1$ was involved as a planner throughout the duration of the project. He explained that the design of project was not really complex but there were many delay events mainly occurred due to the client's and engineer's late selection and approval of materials and equipment for the project. Those events were also not too complex. $\mathrm{C} 1$ opined that any simple delay analysis method could support the contractor's entitlement. However, C1 chose TIA because according to him, having experience in similar projects in UAE, clients would normally require a sophisticated DAM before they give their consent on the analysis method. It can be seen here that the delay analyst $\mathrm{C} 1$ took a decision to select a method based on one factor only, which is the 'the attitude of the opponent party' and almost ignored all other factors. C1 performed TIA on the project but he explained that he kept things at a high level of detail so that the effort, time and cost of performing the analysis remain reasonable. It took him almost three weeks to complete the whole analysis. $\mathrm{C} 1$ explained that he had 
several meetings and discussions with the client representative who had some comments on some of the events. They eventually reached an agreement and the client accepted the analysis and awarded the EoT of 62 days as claimed.

\section{Project D - A Sewage Treatment Plant}

Table 7. Summary of the Sewage Treatment Plant Project

\begin{tabular}{|l|l|}
\hline Location: UAE & Approximate value: 1.5b USD \\
\hline Planned start date: 15 April 2007 & Actual start: 15 April 2007 \\
\hline Planned completion date: 15 April 2009 & Actual completion: 15 October 2009 \\
\hline Main cause of delay: Late design and variation orders & Purpose of delay analysis: Support an EoT claim \\
\hline
\end{tabular}

The records of Project D, a sewage treatment plant project (summary of which is given in Table 7), revealed that there was no claim on delay filed by main contractor during the project execution. A claim was only raised after completion of the project using $\mathrm{APvAB}$ method but it was not accepted by the client. An arbitration case was then filed and a revised delay analysis was done using TIA. Both DAMs suggested an EoT entitlement of 183 days. The case was still ongoing but there were positive signs that the client was going to accept the revised analysis.

\section{Delay Analyst D1}

D1 was a third party delay analyst who was involved in the project to prepare the delay analysis as a part of the final claim submission by the contractor. He explained that he got involved late after the completion of project. Before selection of an appropriate DAM, he first checked whether there was any contractual requirements. D1 then reviewed project records along with the project baseline and the delay events to judge on the nature and complexity of the case. He explained that he found the case 
very complex and performing a sophisticated delay analysis such as TIA would consume huge amount of time and effort and may not produce presentable results. He therefore decided to use the $\mathrm{APvAB}$ analysis as it provides sophisticated analysis of the as built data and the delay events.

D1 confirmed that the performed analysis using APvAB method was successful and it allowed him to consider all the facts and events within a relatively short time, which was 7 weeks. However, the client appointed an opponent delay consultant who insisted in performing TIA as he claimed that it was the only method that could uncover and deal with the contractor's concurrent delays. D1 explained that he did not accept the claim but found it easier to perform a second analysis than trying to persuade the opponent consultant with the results of the first analysis, especially when the case was going through arbitration proceedings. He then performed revised delay analysis using TIA in full coordination with the other party's expert which took around 32 weeks to complete. D1 highlighted that the projects had 120 delay events.

When D1 was asked about the main difference between the two analyses, he explained that in the $\mathrm{APvAB}$ method he analysed the project delays separately and then searched for the potential causes of delay within the 120 events. In the analysis outcome it was found that there were only 12 critical events. However, with TIA he had to analyse the whole 120 events as if they were all critical before discovering that only 12 events were critical, and achieving the same results as that after using the APvAB method. This explains the huge difference in the time required to perform the analysis using the two different methods. D1 however added that unfortunately one would never know or be confident of such result unless the analysis has been completed. The client's 
expert was then satisfied with the results and there were positive signs that the client was reconsidering his stance.

\section{Project $E-A$ Residential Tower}

Table 8. Summary of the residential tower project

\begin{tabular}{|l|l|}
\hline Location: UAE & Approximate value: 25m USD \\
\hline Planned start date: 15 April 2006 & Actual start: 15 April 2006 \\
\hline Planned completion date: 10 October 2008 & Actual completion: 16 December 2008 \\
\hline Main cause of delay: Variation orders & Purpose of delay analysis: Support an EoT claim \\
\hline
\end{tabular}

Project E was a construction project of 32-storey high residential tower in Dubai, UAE - summary of which is given in Table 8. Its value was around $25 \mathrm{~m}$ US Dollars. It suffered with a number of delay events due to variation orders. The project records show that there was only one EoT claim submitted and approved in this project. The delay pertaining to EoT was analysed by using the IAP method, and it was done for claiming 67 days of EoT.

\section{Project Planner E1}

E1 was involved in the project since the beginning and he prepared the EoT claim using the IAP method. E1 explained that due to the relatively small size of the project and the limited number of events, he decided to use a simple method that can produce acceptable results. E1 also noted that the IAP method was found to be suitable because the contract clauses did not require any specific method while the project was running, and the effects of some of the events required a theoretical prediction. E1 performed the whole analysis in 1 week. It is worth noting that E1 did consider an 
important factor which is the status and nature of project while selecting DAM. E1 substantiated the claim with extended narratives explaining the nature and effect of each of the events so that the analysis would sound more credible than just a theoretical analysis. It appears that such extended narratives are reasonable considering the criticisms on the theoretical nature of IAP. The project engineer and the client eventually accepted the EoT claim of 67 days as it was presented.

\section{Further Analysis of the Projects}

A range of similarities and differences were identified between the analysed projects. Table 9 summarises the used DAMs and the main factors considered in selecting the methods. In terms of the commonly used methods, it can be seen that TIA was most frequently used DAM - used in 4 of the 5 analysed case studies. This area may need further research as SCL (2002) generally considered the TIA method as the preferred method, but SCL (2017) noted that the TIA method may not be adequate when analysing delays at a time distant from the event; i.e. after completion of the project when the actual effect of the delay events is known. Livengood (2017) highlighted that the TIA method is proven by a nearly universal adoption but also highlighted various limitation in the method, particularly when applying the method retrospectively.

The surprising fact was that the IAP method, although highly criticised by the researchers and rejected by clients (Yang and Kao 2009; Yusuwan and Adnan 2013), was still commonly used and believed to be effective in at least one of the projects.

The float mapping method, which is not one of the common delay analysis methods, was used in one of the projects but did not deliver the desired results due to its complexity and lack of ability to deal with concurrent delays. This finding is in line with the observation suggested by Mohan and Al-Gahtani (2006). Similarly, the APvAB 
method was used in one of the projects, and as suggested by Arditi and Pattanakitchamroon (2006), Yusuwan and Adnan (2013) and Williams (2003), it was not successful because it was not a preferred method and clients had doubts about its utility and outcome. SCL (2017) and Nelson and Livengood (2017) explained that an enhanced version of the $\mathrm{APvAB}$ method, which is done in widows, may overcome he issues within the $\mathrm{APvAB}$. Further research in this area may be needed to investigate the adoption of the APvAB windows analysis in practice.

Most of the interviewed project planners expressed their view that IAP method should be used when appropriate, particularly when the analysis is from the contractor's perspective. This area may need further practical investigation, as the researchers such as Arditi and Pattanakitchamroon (2006), Braimah and Ndekugri (2008), Yang and Kao (2009) and Yusuwan and Adnan (2013) generally criticise the use of IAP method. SCL (2017) stated that the IAP has material limitations as it does not consider actual progress or change in sequence.

In terms of the importance and consideration of the factors before selecting DAM, although some differences were found in the projects, the interviewees appear to be in agreement on how such factors affected the selection of the method and the level of analysis details.

Table 9. The Delay Analysis Methods and the Main Factors Considered in Selecting Them

\begin{tabular}{|l|l|l|l|}
\hline Project & Interviewee & Used Method(s) & The Main Factors Considered in Selecting the Methods \\
\hline & A1 & IAP & $\begin{array}{l}\text { Available records } \\
\text { Project complexity } \\
\text { Contractual requirements }\end{array}$ \\
\cline { 2 - 4 } & \multirow{3}{*}{ A2 } & Float Mapping & $\begin{array}{l}\text { Available records } \\
\text { Project complexity } \\
\text { Attitude of opponent party } \\
\text { Skills of the analyst } \\
\text { Ownership of the float }\end{array}$ \\
\cline { 2 - 4 } & A3 & $\begin{array}{l}\text { Available records } \\
\text { Project complexity } \\
\text { Contractual requirements } \\
\text { Status of project } \\
\text { Capabilities of the method }\end{array}$ \\
\hline
\end{tabular}




\begin{tabular}{|c|c|c|c|}
\hline & & & $\begin{array}{l}\text { Number of events } \\
\text { Concurrent delays }\end{array}$ \\
\hline \multirow[b]{2}{*}{ B } & B1 & IAP & $\begin{array}{l}\text { Available records } \\
\text { Project complexity } \\
\text { Contractual requirements } \\
\text { Number of events }\end{array}$ \\
\hline & B2 & TIA & $\begin{array}{l}\text { Available records } \\
\text { Project complexity } \\
\text { Contractual requirements } \\
\text { Skills of the analyst } \\
\text { Capabilities of the method } \\
\text { Concurrent delays }\end{array}$ \\
\hline $\mathrm{C}$ & $\mathrm{C} 1$ & TIA & $\begin{array}{l}\text { Available records } \\
\text { Project complexity } \\
\text { Contractual requirements }\end{array}$ \\
\hline D & D1 & $\begin{array}{l}\text { APvAB } \\
\text { TIA }\end{array}$ & $\begin{array}{l}\text { Available records } \\
\text { Project complexity } \\
\text { Contractual requirements } \\
\text { Attitude of opponent party } \\
\text { Status of project } \\
\text { Capabilities of the method } \\
\text { Number of events } \\
\text { Concurrent delays }\end{array}$ \\
\hline $\mathrm{E}$ & E1 & IAP & $\begin{array}{l}\text { Project complexity } \\
\text { Contractual requirements } \\
\text { Attitude of opponent party } \\
\text { Status of project } \\
\text { Capabilities of the method } \\
\text { Number of events }\end{array}$ \\
\hline
\end{tabular}

While all interviewees explained that the consideration of the factors will vary depending on each project circumstances, the main factors considered were the availability of records, the time available to perform the analysis, the attitude of the other party, the contractual requirements and the actual status of the project at the time of performing the analysis. The main factors that were found to be influencing the acceptance of the method were the attitude of opponent party (the client in this context) and the purpose of the delay analysis which were all highlighted by Avalon (2017). An important finding however was that the selection of the method itself is a subjective decision of each delay analyst based on his/her own understanding, interpretation and appreciation of the various factors. This indicates that internal stakeholder management has influence on the selection of the delay analysis methodology in addition to its effect on project delays as suggested by Al-Fadhali et al. 2017 and Zainal et al. 2017. 
Interestingly, the reputation and creditability of the delay analyst were found to be a driving factor for acceptance of DAM. Such a factor has not been so far addressed in the literature. Clients seems to be relying on analysts while making their decision on the proposed method. As such, the reputation and creditability of the delay analyst should also be considered as a plausible factor that affects the selection of DAM.

There was an agreement that the first factor to check is whether the contract documents specify which delay analysis method should be used, which is in line with Avalon (2017) recommendation. Although SCL (2002) and SCL (2017) suggested that new forms of contract nowadays specify DAM, none of the analysed projects had such requirement. Another set of important factors for the selection of DAM were the availability of project records and the time available for performing analysis. The interviewees also viewed the availability of an adequate baseline schedule as part of the project record as an essential element for performing delay analysis. This finding is in line with the works of Arditi and Pattanakitchamroon (2006) and Braimah and Ndekugri (2008) who suggested that a baseline schedule would be required to perform any kind of delay analysis, although its importance may vary.

The interviewees also agreed on the importance of complexity of the project and delay events as a factor. In fact, the project data revealed that this factor was considered while selecting DAM and deciding the level of analysis details. An example of this can be seen in Project $\mathrm{C}$ where the analysis was performed at a high level of detail although the project was relatively not so complex and the claim amount (claimed EoT days) was relatively minor.

Only one of the interviewees, A2, gave high importance to the experience of delay analyst while others viewed it as a secondary factor. This could be because he was performing the float mapping method which was not a common method and it might 
require special experience. SCL (2002), Braimah and Ndekugri (2008) and Avalon (2017) emphasised on the importance of this factor as it may affect both the decision on selection of the method and the acceptance of the results of analysis.

Cost and time limitations were viewed as constraints for both the selection of DAM and level of analysis details. Braimah and Ndekugri (2008) view this factor as a dominant factor for the selection of method. Avalon (2017) also argued that this factor is the most important after the consideration of the contractual requirements. The analysed project data showed that the cost and time limitations were among the driving factors for the DAM selection. For example, the contractors were using the IAP method, not only because it may give them favourable results, but also because it is the most efficient in terms of time and cost.

The strength of DAM was considered as a default factor that have to be reviewed early in the selection process. In projects A, B and D, it was clear, for example, that the IAP method was rejected for its inability to consider actual progress or to deal with the concurrent delay issues. In fact, this factor could be viewed as relevant to the consideration of concurrency issue as suggested by Williams (2003).

The actual status of the project and the time of performing the analysis were viewed by most of the interviewees as the second primary factor after the availability of project records. It was mentioned by all of them and seems to have influenced all the actual selection. For example, for the only running project with a predictable impact of delay events in project E, E1 appears to have relied on this factor while selecting the method.

The last thing to mention is that all interviewees were using Primavera as a software and preferred the 'retained logic' as a scheduling setting as opposed to the 'progress override' option. However, none of them considered this to have any 
influence on the selection of DAM. This may require further investigation as Arditi and Pattanakitchamroon (2006) emphasised on the importance of this factor and highlighted that changes on the scheduling settings of the software may change the results of the whole analysis.

\section{Conclusions}

Many researchers have identified multiple factors affecting the selection of DAMs, but at the same time they argued that DAMs tend to be more context specific, and therefore further studies in different contexts are needed. This research investigates the decision making process to select a DAM in the UAE construction industry. The factors and circumstances affecting the selection of DAMs have been explored on the basis of the interpretive data related to five local construction projects in UAE.

The research identified two DAMs - TIA and IAP - that were commonly used, with TIA emerging as the clients favoured. The analysis of the project cases demonstrated how the reputation and impartiality of the delay analyst is one of the critical factors affecting the selection of DAMs. This factor has not been so far explored and discussed in the literature. Although all delay analysts have considered most of the relevant factors, the analysis of interview data showed that the selection of DAMs are affected by the delay analyst's personal preference. Such preference would be shaped by their own experience, knowledge and understanding. Hence, the delay analyst's profile should be considered vis-à-vis the attitude of the client toward how delays should be handled.

Any specified DAM in the contract documents is expected to be the initial trigger in considering the selection of method. However, none of the project cases contained such specific requirement in its contract documents. The analysts seem to give considerable consideration when selecting a DAM that such a decision process can 
be justified and defended. The availability of project records, quality of the baseline schedule, actual status of the project and the time need to perform the analysis have been identified as the primary factors influencing the selection of DAMs. The complexity of the project and delay events were found to be secondary factors in selecting a DAM but they were primary factors for the decision on the level of analysis detail.

Issues relating to concurrent delay, acceleration and mitigation were considered as secondary in the literature. However, the research has shown that they need to be analysed at an early stage in the selection process in parallel to the process of considering the attitude of the opponent party. Time and budget constraints were also important factors that influenced the selection of DAM and the level of detailed analysis that needs to be carried out by the analyst. The case analysis also showed that when the delay analysts were an impartial third party, these factors became secondary. However, when an in-house analyst was involved, such factors along with the influence of the organization culture and motivation became the primary selection factors.

The skills of the delay analyst were also found to be an influencing factor in the selection of DAM. This factor should be considered in parallel with the attitude of the opponent party and reputation and impartiality of the delay analyst. The literature review suggested that float ownership, software used and scheduling settings are also some of the factors affecting the selection of DAM. However, the practitioners' view in the analysed projects was that these elements may affect the complexity and the way the analysis is carried out, but they would not affect the selection process of DAM nor the depth of the analysis.

In summary, this research showed that in spite of having the knowledge about pros and cons of different DAMs, the appropriateness of using any method, in the 
absence of any contractual requirements, remains at the discretion of the delay analysts. This decision is greatly influenced by their understanding and appreciation of the DAMs and the context of project. The literature and the project cases showed that using different DAMs might produce different results although none of the interviewees claimed that any of the methods was completely wrong. The delay analyst's main objective, at the end of the day, seems to be to persuade all relevant parties that his/her analysis has produced the most reasonable evaluation of the impact of delay events.

The generalisation of the findings of this research could be limited by the fact that the analysis is based on a limited number of case studies on projects implemented between 2007 and 2012 during which projects in the UAE were experiencing a significant financial pressures due to the global financial crisis of 2008/2009. Further study with wider range of projects might help to explore other DAMs in use and the factors affecting their selection, particularly, examining the applicability of SCL's (2017) APvAB windows analysis method. Another line for further research could be to conduct an ethnographic study that will provide opportunity to capture real and live state of knowledge on the selection and use of DAMs.

\section{References}

AL-Fadhali N., Soon N.K., Zainal R., Ahmad A.R., Hasaballah A.H.A. (2018). "Influential Factors in Construction Industry of Yemen." Proceedings of the 21st International Symposium on Advancement of Construction Management and Real Estate, Springer, Singapore, 927-943.

Al-Fadhali, N., Zainal, R., Kasim, N., Dodo, M., Soon, N. K., and Hasaballah, A. A. (2017). "The desirability of Integrated Influential Factors (IIFs) Model of internal stakeholder as a panacea to project completion delay in Yemen." International Journal of Construction Management, 17 (11), 1-9, DOI: 10.1080/15623599.2017.1390720. 
Al-Fadhali, N., and Zainal R. (2017). "A Theoretical Framework on Factors Causing Delay of Construction Industries Projects.” The Social Sciences, 12 (3), 393399.DOI: 10.3923/sscience.2017.393.399.

Alkass, S., Mazerolle, M., Tribaldos, E. and Harris, F. (1995). "Computer aided construction delay analysis and claims preparation." Construction Management and Economics, 13 (4), 335-352.

Arabian Business (2017) "Dubai Construction Projects worth \$818.2bn in November", 27 November 2017, http://www.arabianbusiness.com/industries/construction/384504dubai-construction-projects-worth-8182bn-in-november.

Arditi, D. and Pattanakitchamroon, T. (2006). "Selecting a delay analysis method in resolving construction claims." International Journal of Project Management, 24 (2), 145-155.

Assaf, A. and Al-Hejji, S. (2006). "Causes of delay in large construction projects." International Journal of Project Management, 24 (4), 349-357.

Association for Advancement of Cost Engineering International (AACEI) (2011). "Forensic schedule analysis. Recommended practice 29R-03." <http://www.aacei.org $>$ (Mar. 10, 2015).

Avalon, A. (2017). "Choosing the Most Appropriate Schedule Analysis Method." Cost Engineering Journal, March/April 2017, 12-19.

Braimah, N. and Ndekugri, I. (2008). "Factors influencing the selection of delay analysis methodologies." International Journal of Project Management, 26 (8), 789799.

Bubshait, A. and Cunningham, J. (1998). "Comparison of delay analysis methodologies." Construction and Engineering Management, 124 (4), 315-322.

D’Onofrio, R. (2015). “Ranking AACE International's forensic schedule analysis methodologies." Cost Engineering Journal, July/ August 2015, 4-10.

Denzin, N.K. and Lincoln, Y.S. (2000). "The Discipline and Practice of Qualitative Research". In Denzin, N.K. and Lincoln, Y.S. (eds.), Handbook of Qualitative Research, Thousand Oaks, Sage Publications, $2^{\text {nd }}$ edition, pp.1-28.

Elawi, G. S. A., Algahtany, M., and Kashiwagi, D. (2016). “Owners' Perspective of Factors Contributing to Project Delay: Case Studies of Road and Bridge Projects in Saudi Arabia”. Procedia Engineering, 145, 1402-1409. DOI: 10.1016/j.proeng.2016.04.176

Emam, H.; Mohamed, A. and Farrell, P. (2014). "Causes of delay in GCC construction projects: A Critical Review". $1^{\text {st }}$ International Conference on Smart, Sustainable and Healthy Cities [CIB-MENA], Abu Dhabi, UAE, Volume: pp. 607-621 10.13140/2.1.1211.8086. 
Fellows, R. and Liu, A. (2008). Research Methods for Construction. Blackwell Publishing Ltd, West Sussex.

Kao, C. and Yang, J. (2009). "Comparison of windows-based delay analysis methods." International Journal of Project Management, 27 (4), 408-418.

Kraiem, Z. and Diekmann, J. (1987). "Concurrent delay in construction projects." Journal of Construction Engineering Management ASCE, 113 (4), 591-602.

Kumaraswamy, M. and Yogeswaran, K. (2003). "Substantiation and assessment of claims for extensions of time.” International Journal of Project Management, 21 (1), 27-38.

Livengood, J. (2017). "Retrospective TIA - Is There a Better Way?" Cost Engineering Journal, March/ April 2017, 21-33.

Mohan, S. B. and Al-Gahtani, K. S. (2006). "Current delay analysis techniques and improvement”. Cost Engineering, 48 (9), 12-21.

Nelson, R. and Livengood, J. (2017). "Mixed Forensic Schedule Analysis Methodologies - Proceed with Caution." Cost Engineering Journal, November/ December 2017, 4-9.

Ng, S.T. and Skitmore, R.M. and Deng, M.Z.M. and Nadeem, A. (2004). "Improving Existing Delay Analysis Techniques for the Establishment of Delay Liabilities." Construction Innovation, 4 (8), 3-17.

Perera, N. A., Sutrisna, M. and Yiu, T. W. (2016). "Decision-making model for selecting the optimum method of delay analysis in construction projects." Journal of Management in Engineering, ASCE, 32 (5). 1-14.

Ruqaishi, M., and Bashir, H. 2015. "Causes of Delay in Construction Projects in the Oil and Gas Industry in the Gulf Cooperation Council Countries: A Case Study.” Journal of Management in Engineering 31 (3): 501-517.

Sambasivan, M., and Soon, Y. 2007. "Causes and Effects of Delays in Malaysian Construction Industry.” International Journal of Project Management 25: 517-526.

Society of Construction Law (SCL) (2017). "Society of Construction Law Delay and disruption protocol." < https://www.scl.org.uk> (Nov. 1, 2017).

Society of Construction Law (SCL) (2015). "Rider:1 Society of Construction Law the Delay and disruption protocol." < https://www.scl.org.uk> (Sep. 10, 2015).

Society of Construction Law (SCL) (2002). "Delay and disruption protocol." <http://www.eotprotocol.com> (Dec. 15, 2014).

Vidalis, M.S and Najafi, T.F. (2002). "Cost and time overruns in highway construction." CSCE $4^{\text {th }}$ Transportation Speciality Conference, The Canadian Society for Civil Engineering, Montreal, Quebec, Canada. 5-8 June. 
Williams, T. (2003). "Assessing extension of time delays on major projects." International Journal of Project Management, 21 (1), 19-26.

Yang, J. and Kao, C. (2009). "Review of delay analysis methods: A process-based comparison." The Open Construction and Building Technology, 3, 81-89.

Yusuwan, N. M. and Adnan, H. (2013). "Assessing extension of time application in Malaysian construction industry: Views from professionals." Social and Behavioural Sciences, 105, 54-63.

Zainal, R., AL-Fadhali, N.,Kasim, N., Sarpin, N. (2017) Integrated Influential Factors (IIFs) Model of Internal Stakeholder Causing Project Completion Delay In Yemen Construction Industry Using Amos-Sem Approach, International Journal of Engineering and Technology (IJET), Engg Journals Publications , 9 (5), 3967-3978, ISSN:09754024. DOI: 10.21817/ijet/2017/v9i5/170905004.

Zarei, B., Sharifi, H. and Chaghouee, Y. (2017). "Delay causes analysis in complex construction projects: a Semantic Network Analysis approach." Production Planning \& Control, 29:1, 29-40, DOI: 10.1080/09537287.2017.1376257. 